\title{
Transcriptome-wide map of $\mathrm{m}^{6} \mathrm{~A}$ circRNAs identified in a rat model of hypoxia mediated pulmonary hypertension
}

\author{
Hua Su, Guowen Wang, Lingfang Wu, Xiuqing Ma, Kejing Ying and Ruifeng Zhang*
}

\begin{abstract}
Background: Hypoxia mediated pulmonary hypertension $(\mathrm{HPH})$ is a lethal disease and lacks effective therapy. CircRNAs play significant roles in physiological process. Recently, circRNAs are found to be $\mathrm{m}^{6} \mathrm{~A}$-modified. The abundance of circRNAs was influenced by $m^{6} A$. Furthermore, the significance of $m^{6} A$ circRNAs has not been elucidated in $\mathrm{HPH}$ yet. Here we aim to investigate the transcriptome-wide map of $\mathrm{m}^{6} \mathrm{~A}$ circRNAs in $\mathrm{HPH}$.
\end{abstract}

Results: Differentially expressed $m^{6} A$ abundance was detected in lungs of $\mathrm{HPH}$ rats. $\mathrm{M}^{6} \mathrm{~A}$ abundance in circRNAs was significantly reduced in hypoxia in vitro. $M^{6} A$ circRNAs were mainly from protein-coding genes spanned single exons in control and HPH groups. Moreover, $\mathrm{m}^{6} \mathrm{~A}$ influenced the circRNA-miRNA-mRNA co-expression network in hypoxia. $\mathrm{M}^{6} \mathrm{~A}$ circXpo6 and $\mathrm{m}^{6} \mathrm{~A}$ circTmtc3 were firstly identified to be downregulated in $\mathrm{HPH}$.

Conclusion: Our study firstly identified the transcriptome-wide map of $\mathrm{m}^{6} \mathrm{~A}$ circRNAs in $\mathrm{HPH}$.

$\mathrm{M}^{6} \mathrm{~A}$ can influence circRNA-miRNA-mRNA network. Furthermore, we firstly identified two $\mathrm{HPH}$-associated $\mathrm{m}^{6} \mathrm{~A}$ circRNAs: circXpo6 and circTmtc3. However, the clinical significance of $\mathrm{m}^{6} \mathrm{~A}$ circRNAs for HPH should be further validated.

Keywords: $m^{6} A$ circRNAs, Hypoxia mediated pulmonary hypertension, $m^{6} A$ circXpo6, $m^{6} A$ circTmtc3

\section{Background}

Pulmonary hypertension $(\mathrm{PH})$ is a lethal disease and defined as an increase in the mean pulmonary arterial pressure $\geq 25$ $\mathrm{mmHg}$ at rest, as measured by right heart catheterization [1]. Hypoxia mediated pulmonary hypertension ( $\mathrm{HPH}$ ) belongs to group III PH according to the comprehensive clinical classification of $\mathrm{PH}$, normally accompanied by severe chronic obstructive pulmonary disease (COPD) and interstitial lung diseases [2]. HPH is a progressive disease induced by chronic hypoxia [1]. Chronic hypoxia triggers over-proliferation of pulmonary artery endothelial cells (PAECs) and pulmonary artery smooth muscle cells (PASMCs), and activation of quiescent fibroblasts, the hallmark of HPH $[1,3]$. The pathological characteristics of $\mathrm{HPH}$ are pulmonary vascular remolding, pulmonary hypertension, and right ventricular hypertrophy (RVH) [4]. So far there is no effective therapy for HPH [2]. More effective therapeutic targets are needed to be discovered.

* Correspondence: zhangruifeng@zju.edu.cn

Department of Respiratory Medicine, Sir Run Run Shaw Hospital, Zhejiang University School of Medicine, 3 East Qingchun Road, Hangzhou, China
Circular RNAs (circRNAs) were firstly found abundant in eukaryotes using RNA-seq approach [5-7]. Pre-mRNA is spliced with the $5^{\prime}$ and 3 ' ends, forming a 'head-to-tail' splice junction, then circRNAs are occurred [5]. According to the genome origin, circRNAs may be classified into four different subtypes: exonic circRNA, intronic circRNA, exon-intron circRNA and tRNA introns circRNA [5]. CircRNAs are reported to play crucial roles in miRNA binding, protein binding, regulation of transcription, and posttranscription $[5,8]$. Recent reports indicated that circRNAs can translate to proteins $[8,9]$. Moreover, circRNAs are widely expressed in human umbilical venous endothelial cells when stimulated by hypoxia $[10,11]$. Up to date, only a few reports mentioned $\mathrm{PH}$-associated circRNAs. CircRNAs expression profile is demonstrated in $\mathrm{HPH}$ and chronic thromboembolic pulmonary hypertension [12]. However, the post-transcript modification of circRNAs in $\mathrm{HPH}$ is still unknown.

$\mathrm{N}^{6}$-methyladenosine $\left(\mathrm{m}^{6} \mathrm{~A}\right)$ is regarded as one part of "epitranscriptomics" and identified as the most universal modification on mRNAs and noncoding RNAs (ncRNAs) in eukaryotes $[13,14]$. DRm ${ }^{6} \mathrm{ACH}$ (D denotes A, U or G; R 


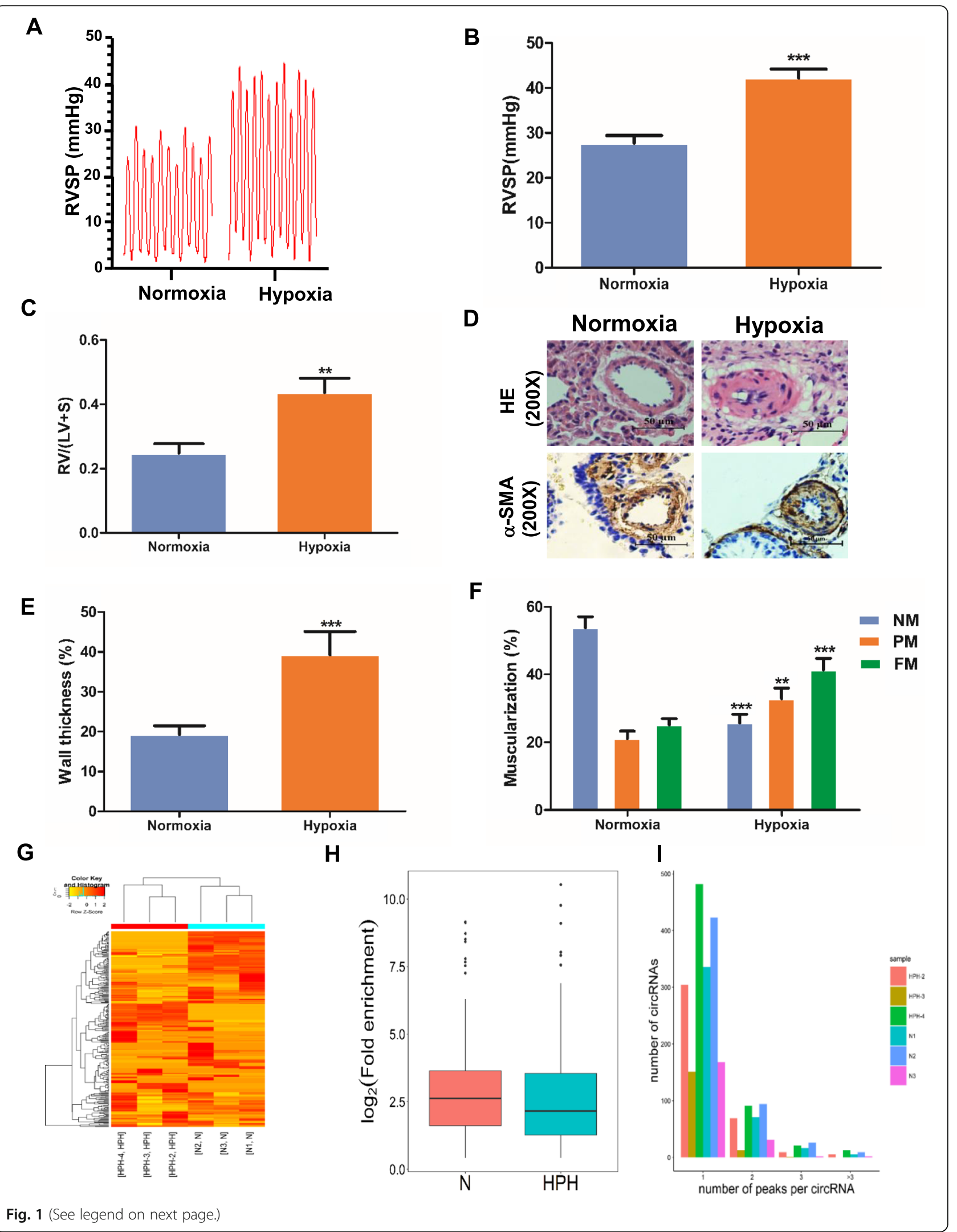


(See figure on previous page.)

Fig. $1 \mathrm{M}^{6} \mathrm{~A}$ level of circRNAs in $\mathrm{HPH}$ rats and the number of $\mathrm{m}^{6} \mathrm{~A}$ peak in circRNAs Rats were maintained in a normobaric normoxic $\left(\mathrm{N}_{1} \mathrm{FiO}_{2} 21 \%\right)$ or hypoxic ( $\mathrm{HPH}, \mathrm{FiO}_{2}$ 10\%) chamber for 3 weeks, then RVSP was detected $(\mathbf{a}, \mathbf{b})$. c The ratio of RV/ (LV+S). $\mathbf{d}$ H\&E staining and

immunohistochemical staining of a-SMA were performed in the lung sections. Representative images of pulmonary small arteries. Scale bar $=$ $50 \mu \mathrm{m}$. Quantification of wall thickness (e) and vessel muscularization (f). $\mathbf{g}$ Heatmap depicting hierarchical clustering of altered $\mathrm{m}^{6} \mathrm{~A}$ circRNAs in lungs of $\mathrm{N}$ and $\mathrm{HPH}$ rats. Red represents higher expression and yellow represents lower expression level. $\mathbf{h}$ Box-plot for $\mathrm{m}^{6} \mathrm{~A}$ peaks enrichment in circRNAs in $\mathrm{N}$ and $\mathrm{HPH}$. i Distribution of the number of circRNAs ( $y$ axis) was plotted based on the number of $\mathrm{m}^{6} \mathrm{~A}$ peaks in circRNAs ( $\mathrm{x}$ axis) in $\mathrm{N}$ and $\mathrm{HPH}$. Values are presented as means \pm SD ( $n=6$ in each group). Only vessels with diameter between 30 and $90 \mu \mathrm{m}$ were analyzed. NM, nonmuscularized vessels; PM, partially muscularized vessels; FM, fully muscularized vessels. ${ }^{* *} 0.001 \leq P \leq 0.009$ (different from $N$ ); ${ }^{* * *} P<0.001$ (different from $\mathrm{N}$ )

denotes $\mathrm{A}, \mathrm{G}$; $\mathrm{H}$ denotes $\mathrm{A}, \mathrm{C}$, or $\mathrm{U}$ ) is a consensus motif occurred in $\mathrm{m}^{6} \mathrm{~A}$ modified RNAs [15-17]. $\mathrm{M}^{6} \mathrm{~A}$ modification is mainly enriched around the stop codons, at 3'untranslated regions and within internal long exons [17-19]. Several catalyzed molecules act as "writers", "readers", and "erasers" to regulate the $\mathrm{m}^{6} \mathrm{~A}$ modification status [14]. The methyltransferase complex is known as writers, including methyltransferase-like-3, - 14 and - 16 (METTL3/ METTL14/METTL16), Wilms tumor 1-associated protein (WTAP), RNA binding motif protein 15 (RBM15), vir like $\mathrm{m}^{6} \mathrm{~A}$ methyltransferase associated (KIAA1429) and zinc finger $\mathrm{CCCH}$-type containing 13 (ZC3H13), appending $\mathrm{m}^{6} \mathrm{~A}$ on DRACH $[17,20,21]$. METTL3 is regarded as the core catalytically active subunit, while METTL14 and WTAP play a structural role in METTL3's catalytic activity [18, 22]. The "erasers", fat mass and obesity related protein (FTO) and alkylation repair homolog 5 (ALKBH5), catalyze the $\mathrm{N}$ alkylated nucleic acid bases oxidatively demethylated [22]. The "readers", the YT521-B homology (YTH) domaincontaining proteins family includes YTHDF (YTHDF1, YTHDF2, YTHDF3), YTHDC1, and YTHDC2, specifically recognizes $\mathrm{m}^{6} \mathrm{~A}$ and regulates splicing, localization, degradation and translation of RNAs [14, 22, 23]. The YTHDF1 and YTHDF2 crystal structures forms an aromatic cage to recognize $\mathrm{m}^{6} \mathrm{~A}$ sites in cytoplasm [24]. YTHDC1 is the nuclear reader and YTHDC2 binds $\mathrm{m}^{6} \mathrm{~A}$ under specific circumstances or cell types [24]. Hypoxia may alter the balance of writers-erasers-readers and induce tumor growth, angiogenesis, and progression [25, 26].

Interestingly, circRNAs can be $\mathrm{m}^{6} \mathrm{~A}$-modified. $\mathrm{M}^{6} \mathrm{~A}$ circRNAs displayed cell-type-specific methylation patterns in human embryonic stem cells and HeLa cells [14]. CircRNAs contained $\mathrm{m}^{6} \mathrm{~A}$ modifications are likely to promote protein translation in a cap-independent pattern [9]. However, $\mathrm{m}^{6} \mathrm{~A}$ circRNAs has not been elucidated in $\mathrm{HPH}$ yet. Here we are the first to identify the expression profiling of $\mathrm{m}^{6} \mathrm{~A}$ circRNAs in $\mathrm{HPH}$.

\section{Results}

$M^{6} A$ level of circRNAs was reduced in $\mathrm{HPH}$ rats and most circRNAs contained one $\mathrm{m}^{6} \mathrm{~A}$ peak

Three weeks treatment by hypoxia resulted in right ventricular systolic pressure (RVSP) elevating to $42.23 \pm 1.96 \mathrm{mmHg}$ compared with $27.73 \pm 1.71$
$\mathrm{mmHg}$ in the control $(P<0.001$, Fig. $1 \mathrm{a}$ and $\mathrm{b})$. The ratio of the right ventricle $(\mathrm{RV})$, left ventricular plus ventricular septum $(\mathrm{LV}+\mathrm{S})[\mathrm{RV} /(\mathrm{LV}+\mathrm{S})]$ was used as an index of RVH. RVH was indicated by the increase of $\mathrm{RV} /(\mathrm{LV}+\mathrm{S})$ compared with the control $(0.25 \pm 0.03$ vs. $0.44 \pm 0.04, P=0.001$, Fig. $1 \mathrm{c})$. The medial wall of the pulmonary small arteries was also significantly thickened $(19.28 \pm 2.19 \%$ vs. $39.26 \pm$ $5.83 \%, P<0.001$, Fig. $1 \mathrm{~d}$ and e). Moreover, in the normoxia group, $53.82 \pm 3.27 \%$ of the arterioles were non-muscularized (NM) vessels, and $25.13 \pm 1.83 \%$ were fully muscularized (FM) vessels. In contrast, partially muscularized vessels (PM) and FM vessels showed a greater proportion $(32.88 \pm 3.15 \%$ and $41.41 \pm 3.35 \%)$ in $\mathrm{HPH}$ rats, while NM vessels occupied a lower proportion $(25.71 \pm 2.55 \%)$ (Fig. 1f). Figure $1 \mathrm{~g}$ displayed the heatmap of $\mathrm{m}^{6} \mathrm{~A}$ circRNAs expression profiling in $\mathrm{N}$ and $\mathrm{HPH} . \mathrm{M}^{6} \mathrm{~A}$ abundance in 166 circRNAs was significantly upregulated. Meanwhile, $\mathrm{m}^{6} \mathrm{~A}$ abundance in 191 circRNAs was significantly downregulated (Additional file 1: Data S1, filtered by fold change $\geq 4$ and $P \leq 0.00001)$. Lungs of $\mathrm{N}$ and $\mathrm{HPH}$ rats were selected to measure $\mathrm{m}^{6} \mathrm{~A}$ abundance in purified circRNAs. The $\mathrm{m}^{6} \mathrm{~A}$ level in total circRNAs isolated from lungs of $\mathrm{HPH}$ rats was lower than that from controls (Fig. 1h). Moreover, over $50 \%$ circRNAs contained only one $\mathrm{m}^{6} \mathrm{~A}$ peak either in lungs of $\mathrm{N}$ or $\mathrm{HPH}$ rats (Fig. 1i).

\section{$M^{6} A$ circRNAs were mainly from protein-coding genes spanned single exons in $\mathrm{N}$ and $\mathrm{HPH}$ groups}

We analyzed the distribution of the parent genes of total circRNAs, $\mathrm{m}^{6} \mathrm{~A}$-circRNAs, and non- $\mathrm{m}^{6} \mathrm{~A}$ circRNAs in $\mathrm{N}$ and $\mathrm{HPH}$, respectively. $\mathrm{N}$ and $\mathrm{HPH}$ groups showed a similar genomic distribution of $\mathrm{m}^{6} \mathrm{~A}$ circRNAs and non- $\mathrm{m}^{6} \mathrm{~A}$ circRNAs (Fig. 2a and b). Moreover, about $80 \%$ of $\mathrm{m}^{6} \mathrm{~A}$ circRNAs and non$\mathrm{m}^{6} \mathrm{~A}$ circRNAs were derived from protein-coding genes in both groups. A previous report indicated that most circRNAs originated from protein-coding genes spanned two or three exons [14]. While in our study, over 50 and $40 \%$ of total circRNAs from protein-coding genes spanned one exon in $\mathrm{N}$ and $\mathrm{HPH}$ groups, respectively (Fig. 2c and d). Similarly, 
A $\mathbf{N}$

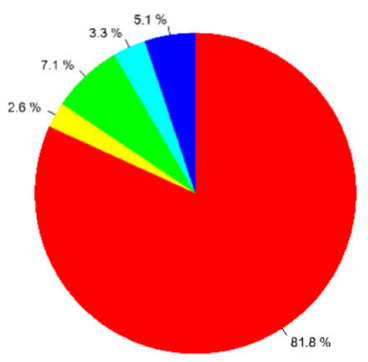

circRNAs

B HPH

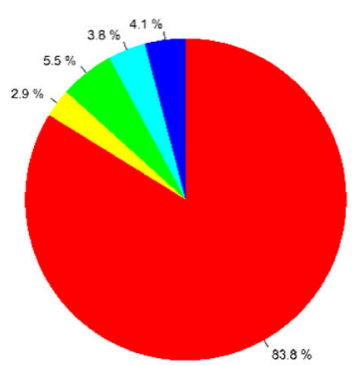

circRNAs

C $\mathbf{N}$

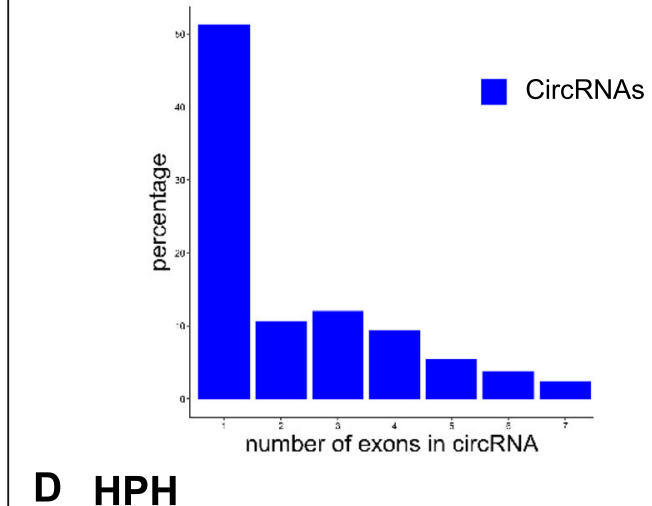

D $\mathrm{HPH}$

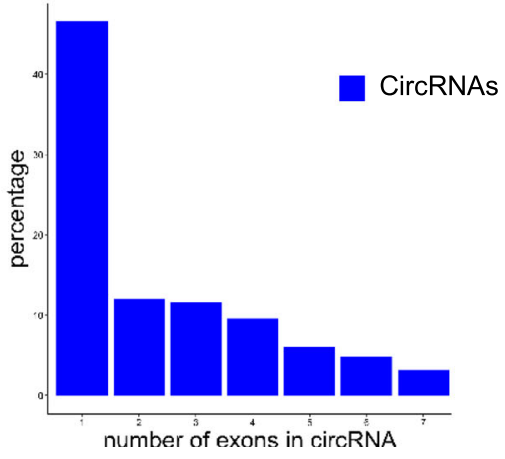

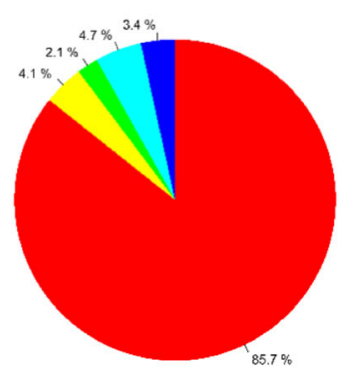

$\mathrm{m}^{6} \mathrm{~A}$ circRNAs

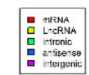

$m^{6} A$ circRNAs

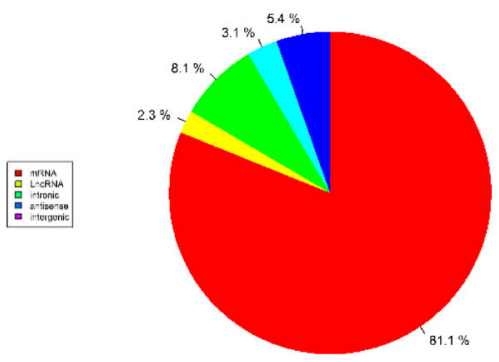

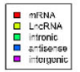

Non-m ${ }^{6} A$ circRNAs
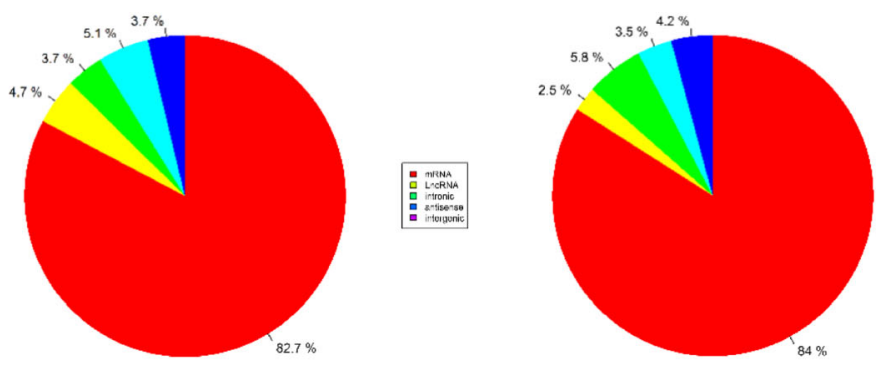

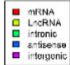

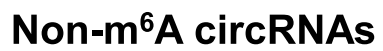

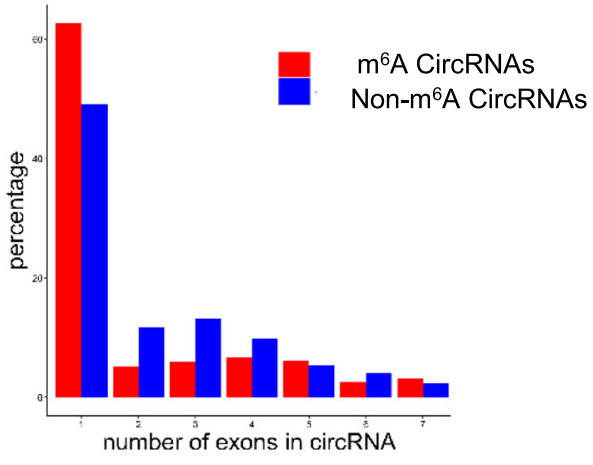

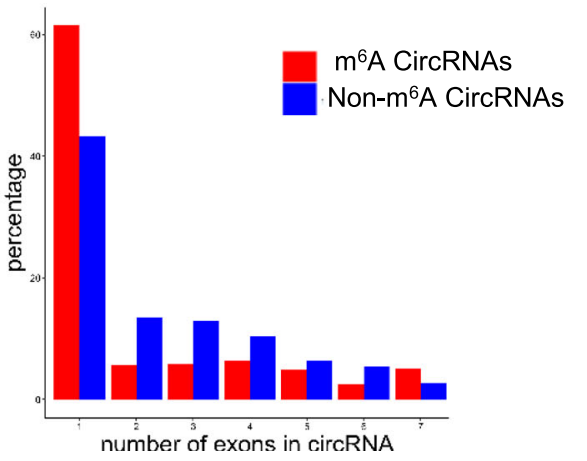

Fig. 2 (See legend on next page.) 
(See figure on previous page.)

Fig. 2 The genomic origins of $m^{6} A$ circRNAs The distribution of genomic origins of total circRNAs (input, left), $m^{6} A$ circRNAs (eluate, center), and non- $\mathrm{m}^{6} \mathrm{~A}$ circRNAs (supernatant, right) in $\mathrm{N}(\mathbf{a})$ and $\mathrm{HPH}(\mathbf{b})$. The percentage of circRNAs (y axis) was calculated according to the number of exons ( $x$ axis) spanned by each circRNA for the input circRNAs (left), $m^{6} A-c i r c R N A s$ (red, right) and non- $m^{6} A$ circRNAs (blue, right) in $N(\mathbf{c})$ and HPH (d).

Up to seven exons are shown

$\mathrm{m}^{6} \mathrm{~A}$ circRNAs and non- $\mathrm{m}^{6} \mathrm{~A}$ circRNAs were mostly encoded by single exons. Therefore, it was indicated that $\mathrm{m}^{6} \mathrm{~A}$ methylation was abundant in circRNAs originated from single exons in $\mathrm{N}$ and $\mathrm{HPH}$ groups.

The distribution and functional analysis for host genes of circRNAs with differentially expressed $\mathrm{m}^{6} \mathrm{~A}$ peaks

The length of differentially-expressed $\mathrm{m}^{6} \mathrm{~A}$ circRNAs was mostly enriched in 1-10,000 bps (Fig. 3a). The host genes of upregulated $\mathrm{m}^{6} \mathrm{~A}$ circRNAs were located in chromosome 1,2 and 10, while the downregulated parts were mostly located in chromosome 1, 2 and 14 (Fig. 3b).

Gene ontology (GO) analysis and Kyoto Encyclopedia of Genes and Genomes (KEGG) pathway analysis were performed to explore the host genes of circRNAs with differentially-expressed $\mathrm{m}^{6} \mathrm{~A}$ peaks. In the GO analysis (Fig. 3c, left), the parent genes of circRNAs with upregulated $\mathrm{m}^{6} \mathrm{~A}$ peaks were enriched in the protein modification by small protein conjugation or removal and macromolecule modification process in the biological process (BP). Organelle and membrane-bounded organelle were also the two largest parts in the cellular component $(\mathrm{CC})$ analysis. Binding and ion binding were the two main molecular functions (MF) analysis. The top 10 pathways from KEGG pathway analysis were selected in the bubble chart (Fig. 3c, right). Among them, the oxytocin signaling pathway, protein processing in endoplasmic reticulum and cGMP-PKG signaling pathway were the top 3 pathways involved. In addition, vascular smooth muscle contraction pathway was the most associated pathway in PH progression [27].

In Fig. 3d left, the parent genes of circRNAs with downregulated $\mathrm{m}^{6} \mathrm{~A}$ peaks were mainly enriched in the cellular protein modification process and protein modification process in BP. Organelle and membrane-bounded organelle made up the largest proportion in the CC classification. The MF analysis was focused on receptor signaling protein activity and protein binding. The parent genes of circRNAs with decreased $\mathrm{m}^{6} \mathrm{~A}$ peaks were mainly involved in the tight junction and lysine degradation in the KEGG pathway analysis (Fig. 3d, right).

\section{Hypoxia can influence the $m^{6} \mathrm{~A}$ level of circRNAs and circRNAs abundance}

$360 \mathrm{~m}^{6} \mathrm{~A}$ circRNAs were shared in $\mathrm{N}$ and $\mathrm{HPH}$ groups. $49 \%$ of $\mathrm{m}^{6} \mathrm{~A}$ circRNAs detected in $\mathrm{N}$ group were not detected in $\mathrm{HPH}$ group, and $54 \%$ of $\mathrm{m}^{6} \mathrm{~A}$ circRNAs detected in $\mathrm{HPH}$ group were not detected in $\mathrm{N}$ group (Fig. 4a). To explore whether $\mathrm{m}^{6} \mathrm{~A}$ methylation would influence circRNAs expression level, expression of the 360 common $\mathrm{m}^{6} \mathrm{~A}$ circRNAs were identified. More circRNAs tended to decrease in $\mathrm{HPH}$ compared to N (Fig. 4b). Moreover, expression of $\mathrm{m}^{6} \mathrm{~A}$ circRNAs was significantly downregulated compared with non- $\mathrm{m}^{6} \mathrm{~A}$ circRNAs in hypoxia, suggesting that $\mathrm{m}^{6} \mathrm{~A}$ may downregulate the expression of circRNAs in hypoxia (Fig. 4c, $P=0.0465$ ).

\section{Construction of a circRNA-miRNA-mRNA co-expression network in $\mathrm{HPH}$}

We found 76 upregulated circRNAs with increased $\mathrm{m}^{6} \mathrm{~A}$ abundance, and 107 downregulated circRNAs with decreased $\mathrm{m}^{6} \mathrm{~A}$ abundance (Fig. 5a, Additional file 2: Data S2, Additional files 3 and 4). As known, circRNAs were mostly regarded as a sponge for miRNAs and regulated the expression of corresponding target genes of miRNAs [28]. To explore whether circRNAs with differentiallyexpressed $\mathrm{m}^{6} \mathrm{~A}$ abundance influence the availability of miRNAs to target genes, we selected differentiallyexpressed circRNAs with increased or decreased $\mathrm{m}^{6} \mathrm{~A}$ abundance. GO enrichment analysis and KEGG pathway analysis were also performed to analyze target mRNAs. Target mRNAs displayed similar GO enrichment in the two groups (Fig. 5b and c). Two main functions were determined in BP analysis: positive regulation of biological process and localization. Intracellular and intracellular parts make up the largest proportion in CC part. Target mRNAs were mostly involved in protein binding and binding in MF part. In the KEGG pathway analysis, the top 10 most enriched pathways were selected (Fig. 5d and e). Wnt and FoxO signaling pathways were reported to be involved in PH progression [29-31]. Then, we analyzed the target genes involved in these two pathways. SMAD4 was associated with $\mathrm{PH}$ and involved in Wnt signaling pathways. MAPK3, SMAD4, TGFBR1, and CDKN1B were involved in FoxO signaling pathways. To explore the influence of circRNA-miRNA regulation on $\mathrm{PH}$-associated genes expression, we constructed a circRNA-miRNAmRNA network, integrating matched expression profiles of circRNAs, miRNAs and mRNAs (Fig. $5 \mathrm{f}$ and g). MicroRNAs sponged by the target genes of interest were analyzed. MiR-125a-3p, miR-23a-5p, miR-98-5p, let-7b-5p, let7a-5p, let-7 g-5p, and miR-205 were analyzed because they were reported to be associated with $\mathrm{PH}[32,33]$. We filtered the key mRNAs and miRNAs, and founded that the two 


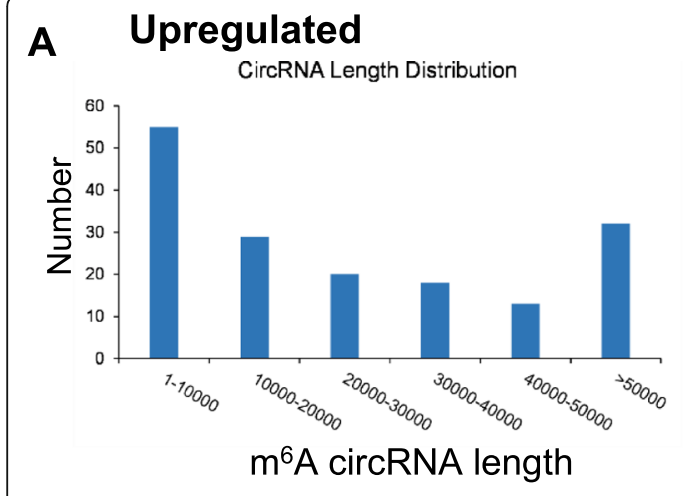

\section{B Upregulated}

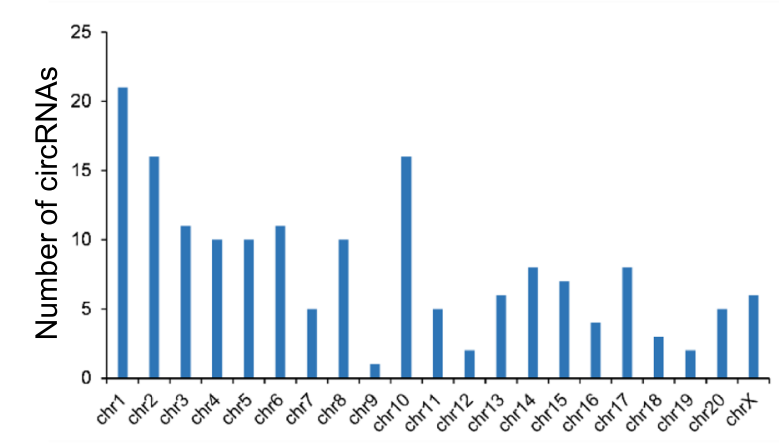

\section{Upregulated}

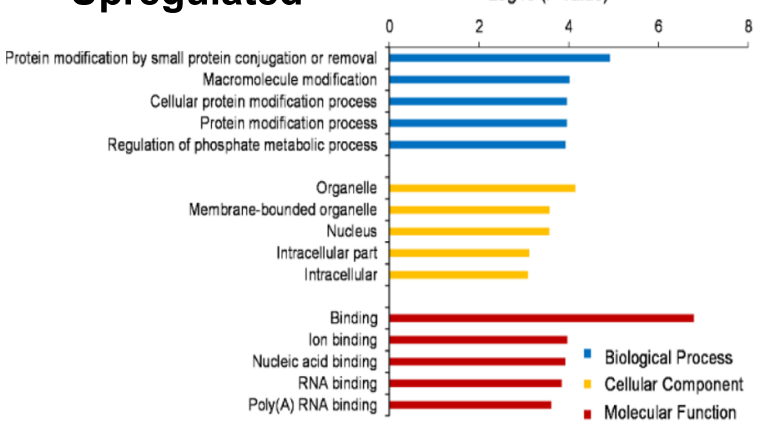

D Downregulated

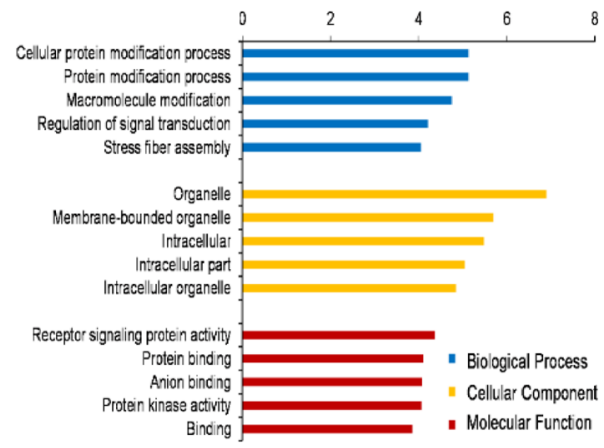

\section{Downregulated}

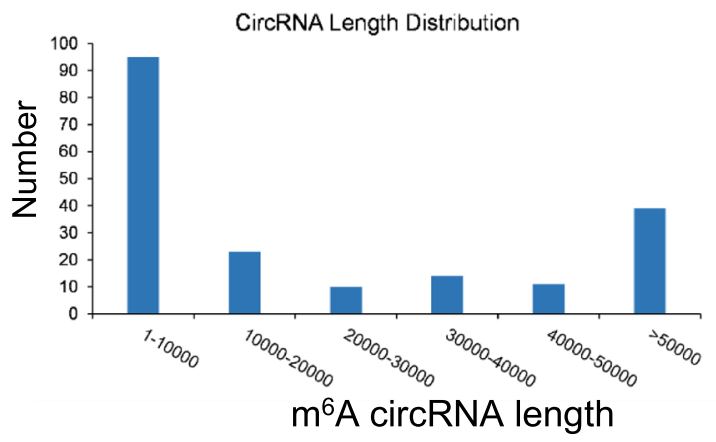

Downregulated

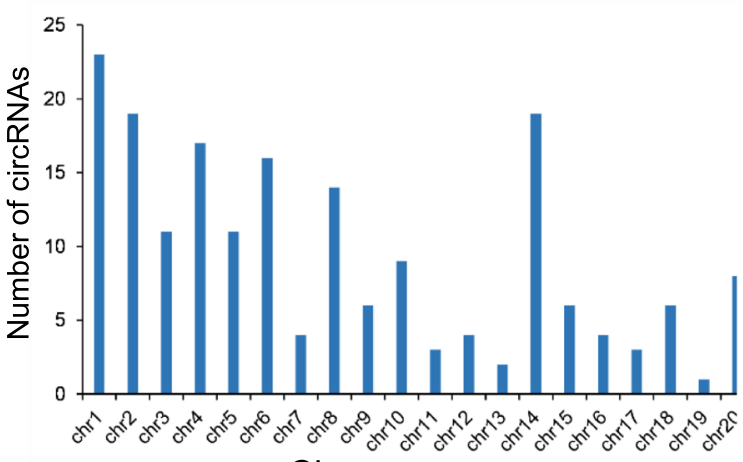

Chromosomes

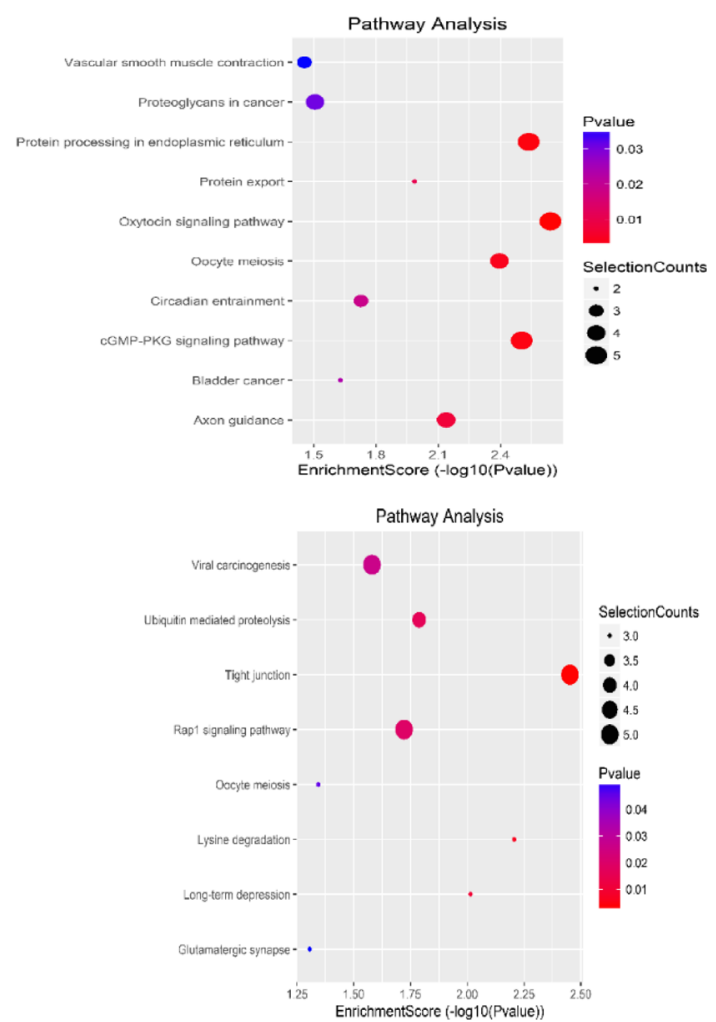

Fig. 3 (See legend on next page.) 
(See figure on previous page.)

Fig. 3 The distribution and functional analysis for host genes of circRNAs with differentially expressed (DE) $m^{6} A$ peaks (a) Length of DE $m^{6} A$ circRNAs. $\mathbf{b}$ The chromosomes origins for host genes of DE $\mathrm{m}^{6} \mathrm{~A}$ circRNAs. GO enrichment and KEGG signaling pathway analysis for host genes of upregulated (c) and downregulated (d) $\mathrm{m}^{6} \mathrm{~A}$ circRNAs. $\mathrm{GO}$ enrichment analysis include biological process (BP) analysis, cellular component (CC) analysis, and molecular function (MF) analysis. $P$ values are calculated by DAVID tool

circRNAs were the most enriched, which were originated from chr1:204520403-204,533,534- (Xpo6) and chr7: 40223440-40,237,400- (Tmtc3).

\section{$M^{6} A$ circXpo6 and $m^{6} A$ circTmtc3 were downregulated in PASMCs and PAECs in hypoxia}

$\mathrm{M}^{6} \mathrm{~A}$ abundance was significantly reduced in PASMCs and PAECs when exposed to hypoxia $(0.107 \% \pm 0.007$ vs. $0.054 \% \pm 0.118, P=0.023$ in PASMCs; $0.114 \% \pm 0.011$ vs. $0.059 \% \pm 0.008, P=0.031$ in PAECs, Fig. 6 a). $\mathrm{M}^{6} \mathrm{~A}$ abundance in circRNAs was lower than it in mRNAs (0.1$0.4 \%)[17,18]$. Next, we confirmed the back-splicing of circXpo6 and circTmtc3 by CIRI software. The sequence of linear Xpo6 and Tmtc3 mRNA was analyzed. Then we identified that circXpo6 was spliced form exon 7, 8, and 9 of Xpo6. CircTmtc3 was spliced form exon 8, 9, 10, and 11 (Fig. 6b). Using cDNA and genomic DNA (gDNA) from PASMCs and PAECs as templates, circXpo6 and circTmtc3 were only amplified by divergent primers in cDNA, while no product was detected in gDNA (Fig. 6c). To identify whether circXpo6 and circTmtc3 were modified by $\mathrm{m}^{6} \mathrm{~A}$, we performed $\mathrm{M}^{6} \mathrm{~A}$ RNA Immunoprecipitation (MeRIP)-RT-PCR and MeRIP-quantitative RT-PCR (MeRIP-qRT-PCR) to detect the expression of circXpo6 and circTmtc3 (Fig. 6d and e). $\mathrm{m}^{6} \mathrm{~A}$ circXpo6 and $\mathrm{m}^{6} \mathrm{~A}$ circTmtc3 were significantly decreased in PASMCs and PAECs when exposed to hypoxia $(P=0.002$, and $P=0.015$ in PASMCs and $P=$ 0.02 , and $P=0.047$ in PAECs).

\section{Discussion}

In this study, we identified the transcriptome-wide map of $\mathrm{m}^{6} \mathrm{~A}$ circRNAs in hypoxia mediated pulmonary hypertension. On the whole, we found that $\mathrm{m}^{6} \mathrm{~A}$ level in circRNAs was reduced in lungs when exposed to hypoxia. $\mathrm{M}^{6} \mathrm{~A}$ circRNAs were mainly derived from single exons of proteincoding genes in $\mathrm{N}$ and $\mathrm{HPH}$. $\mathrm{M}^{6} \mathrm{~A}$ abundance in circRNAs was downregulated in hypoxia in vitro. $\mathrm{M}^{6} \mathrm{~A}$ influenced the circRNA-miRNA-mRNA co-expression network in hypoxia. Moreover, circXpo6 and circTmtc3 were the novel identified circRNAs modified by $\mathrm{m}^{6} \mathrm{~A}$ in hypoxia mediated pulmonary hypertension.

$\mathrm{M}^{6} \mathrm{~A}$ plays important roles in various biological processes. $\mathrm{M}^{6} \mathrm{~A}$ is associated with cancer progression, promoting the proliferation of cancer cells and contributing to the cancer stem cell self-renewal $[18,21]$. Lipid accumulation was reduced in hepatic cells when $\mathrm{m}^{6} \mathrm{~A}$ abundance in peroxisome proliferator-activator ( $P P a R)$ was decreased [34]. Enhanced $\mathrm{m}^{6} \mathrm{~A}$ level of mRNA contributed to compensated cardiac hypertrophy [35]. Also, $\mathrm{m}^{6} \mathrm{~A}$ modification of large intergenic noncoding RNA 1281 was necessary for mouse embryonic stem cells differentiation [36].

Although it has been reported that $\mathrm{m}^{6} \mathrm{~A}$ mRNAs were influenced by hypoxia, there is no report about $\mathrm{m}^{6} \mathrm{~A}$ circRNAs in $\mathrm{HPH}$ yet. Up to now, no consistent conclusion was reached about the link between $\mathrm{m}^{6} \mathrm{~A}$ and hypoxia. Previous reports found that the $\mathrm{m}^{6} \mathrm{~A}$ abundance in mRNA was increased under hypoxia stress in HEK293T cells and cardiomyocytes [37, 38]. The increased $\mathrm{m}^{6} \mathrm{~A}$ level stabilized the mRNAs of Glucose Transporter 1 (Glut1), Myc proto-oncogene bHLH transcription factor (Myc), Dual Specificity Protein Phosphatase 1 (Dusp1), Hairy and Enhancer of Split 1 (Hes1), and Jun ProtoOncogene AP-1 Transcription Factor Subunit (Jun) without influencing their protein level [37]. In contrast, another reported that $\mathrm{m}^{6} \mathrm{~A}$ level of total mRNA was decreased when human breast cancer cell lines were exposed to $1 \% \mathrm{O}_{2}$ [26]. Hypoxia increased demethylation by stimulating hypoxia-inducible factor (HIF)- $1 \alpha$ - and HIF- $2 \alpha$-dependent over-expression of ALKBH5 [26]. In addition, transcription factor EB activates the transcription of ALKBH5 and downregulates the stability of METTL3 mRNA in hypoxia/reoxygenation-induced autophagy in ischemic diseases [38]. Our study found that $\mathrm{m}^{6} \mathrm{~A}$ abundance in total circRNAs was decreased in hypoxia exposure. Moreover, our study indicated that circXpo6 and circTmtc3 were the novel identified circRNAs modified by $\mathrm{m}^{6} \mathrm{~A}$ in $\mathrm{HPH} . \mathrm{M}^{6} \mathrm{~A}$ abundance in circXpo6 and circTmtc3 was decreased in hypoxia. It is probably because of HIF-dependent and ALKBH5mediated $\mathrm{m}^{6} \mathrm{~A}$ demethylation [26].

Previous reports indicated that $\mathrm{m}^{6} \mathrm{~A}$ methylation close to $3^{\prime}$ UTR and stop codon of mRNA is inversely correlated with gene expression $[14,39]$. Low $\mathrm{m}^{6} \mathrm{~A}$ level is negatively associated with circRNAs expression, while high $\mathrm{m}^{6} \mathrm{~A}$ level is not linked to circRNAs expression in human embryonic stem cells and HeLa cells [14]. Consistent with the previous reports [14, 39], our study found that $\mathrm{m}^{6} \mathrm{~A}$ reduced the total circRNAs abundance in hypoxia. The association between $\mathrm{m}^{6} \mathrm{~A}$ level and specific gene abundance is remained as an open question. Some previous reports indicated that $\mathrm{m}^{6} \mathrm{~A}$ level was positively associated with long non-coding RNA 


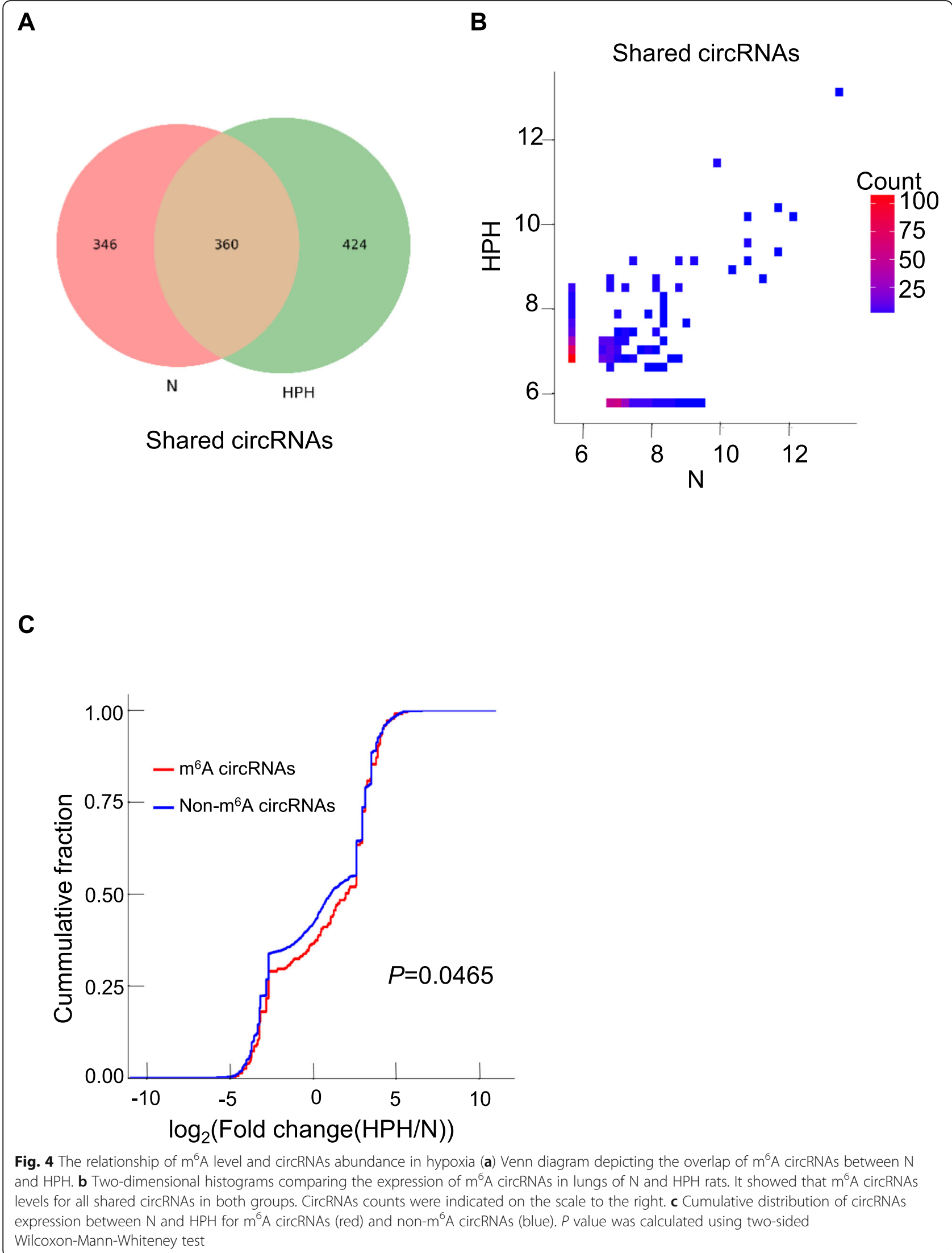




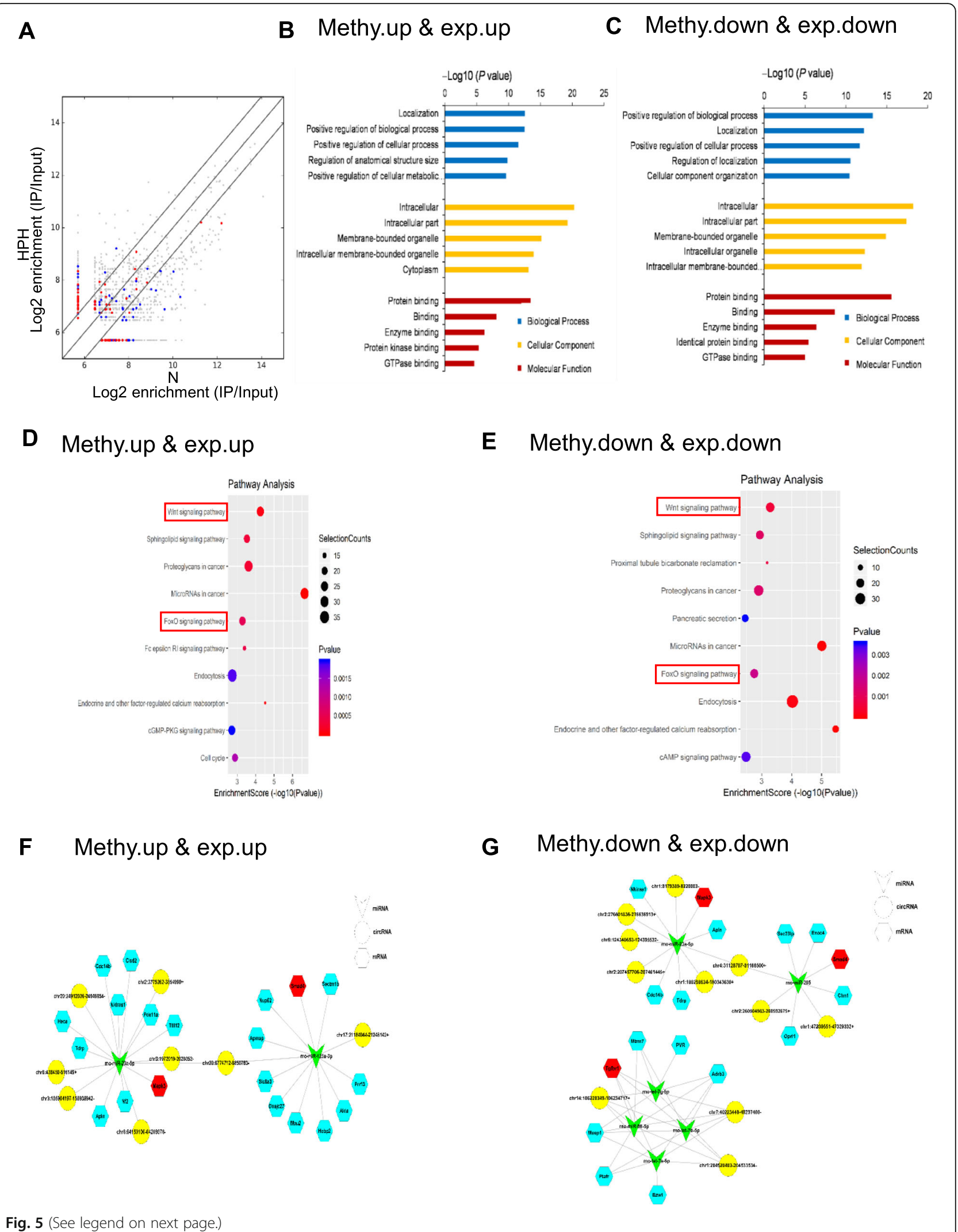




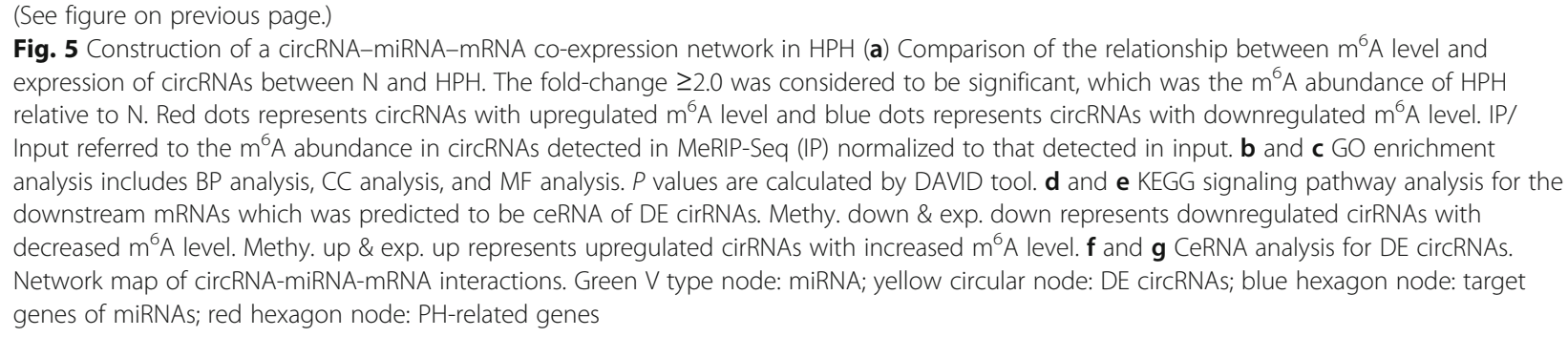

(lncRNA) or mRNA expression [40, 41]. $\mathrm{M}^{6} \mathrm{~A}$ was positively associated with RP11-138 J23.1 (RP11) expression when ALKBH5 was overexpressed in colorectal cancer [40]. mRNAs were downregulated after METTL14 deletion in $\beta$-cells [41]. On the contrary, another reports insisted that $\mathrm{m}^{6} \mathrm{~A}$ level was negatively associated with RNA expression [42-44]. the mRNA lifetime of Family with Sequence Similarity 134, Member B (FAM134B) was prolonged when the $\mathrm{m}^{6} \mathrm{~A}$ site was mutant [42]. The decreased $\mathrm{m}^{6} \mathrm{~A}$ level resulted in the increased expression of $\mathrm{N}$-methyl-D-aspartate receptor 1 (NMDAR1) in Parkinson's disease [43]. Forkhead Box protein M1 (FOXM1) abundance was increased when ALKBH5 was upregulated in glioblastoma [44]. Our study indicated that the expression of circXpo6 and circTmtc3 was decreased with the downregulated $\mathrm{m}^{6} \mathrm{~A}$ level. The association between $\mathrm{m}^{6} \mathrm{~A}$ level and circRNAs abundance was not determined yet. We suspected that $\mathrm{m}^{6} \mathrm{~A}$ may influence the expression of circXpo6 and circTmtc3 through similar manners as before $[40,41]$. But it needs further validation.

Competing endogenous RNA (CeRNA) mechanism was proposed that mRNAs, pseudogenes, IncRNAs and circRNAs interact with each other by competitive binding to miRNA response elements (MREs) $[45,46] . \mathrm{M}^{6} \mathrm{~A}$ acts as a post-transcript regulation of circRNAs and influences circRNAs expression, thus we suggested that $\mathrm{m}^{6} \mathrm{~A}$ could also regulate the circRNA-miRNA-mRNA coexpression network. When the circRNAs were classified, we found that these downstream targets regulated by circRNAmiRNA of interest were mostly enriched in $\mathrm{PH}$-associated Wnt and FoxO signaling pathways $[30,31]$. The $W n t / \beta$-catenin $(\mathrm{bC})$ pathway and Wnt/ planar cell polarity (PCP) pathway are the two most critical Wnt signaling pathways in $\mathrm{PH}$ [30]. As known, the two important cells associated with $\mathrm{HPH}$ are PASMCs and PAECs $[1,3]$. The growth of PASMCs was increased when Wnt/bC and Wnt/PCP pathways were activated by platelet derived growth factor beta polypeptide $\mathrm{b}$ (PDGF-BB) [30, 47]. In addition, the proliferation of PAECs was enhanced when Wnt/bC and Wnt/PCP pathways were activated by bone morphogenetic protein 2 (BMP2). Furthermore, the FoxO signaling pathway is associated with the apoptosis-resistant and hyper-proliferative phenotype of PASMCs [31]. Reactive oxygen species is increased by hypoxia and activates AMPK-dependent regulation of FoxO1 expression, resulting in increased expression of catalase in PASMCs [48]. Our study firstly uncovered that $\mathrm{m}^{6} \mathrm{~A}$ influenced the stability of circRNAs, thus affecting the binding of circRNAs and miRNA, resulting in the activation of Wnt and FoxO signaling pathways.

\section{Conclusion}

In conclusion, our study firstly identified the transcriptomewide map of $\mathrm{m}^{6} \mathrm{~A}$ circRNAs in HPH. $\mathrm{M}^{6} \mathrm{~A}$ level in circRNAs was decreased in lungs of HPH and in PASMCs and PAECs exposed to hypoxia. $\mathrm{M}^{6} \mathrm{~A}$ level influenced circRNA-miRNAmRNA co-expression network in HPH. Moreover, we firstly identified two downregulated $\mathrm{m}^{6} \mathrm{~A}$ circRNAs in $\mathrm{HPH}$ : circXpo6 and circTmtc3. CircRNAs may be used as biomarkers because it is differentially enriched in specific cell types or tissues and not easily degraded [6]. Also, the aberrant $\mathrm{m}^{6} \mathrm{~A}$ methylation may contribute to tumor formation and $\mathrm{m}^{6} \mathrm{~A}$ RNAs may be a potential therapy target for tumor [17].

Limitations still exist in the study. First, we did not analyze the $\mathrm{m}^{6} \mathrm{~A}$ level between circRNAs and the host genes. Second, the exact mechanism of hypoxia influences $\mathrm{m}^{6} \mathrm{~A}$ was not demonstrated. Thirdly, the function of circXpo6 and circTmtc3 in HPH was not elaborated. Lastly, besides hypoxia mediated pulmonary hypertension, many other significant $\mathrm{PH}$ models should also be noted, such as monocrotaline mediated $\mathrm{PH}$, monocrotaline + pneumonectomy mediated $\mathrm{PH}$, and so on. It is insufficient that we explored the expression profiling of $\mathrm{m}^{6} \mathrm{~A}$ circRNAs only in hypoxia mediated pulmonary hypertension. We plan to explore the expression profiling of $\mathrm{m}^{6} \mathrm{~A}$ circRNAs in monocrotaline-induced $\mathrm{PH}$ and other $\mathrm{PH}$ models. Moreover, the clinical significance of $\mathrm{m}^{6} \mathrm{~A}$ circRNAs for $\mathrm{HPH}$ should be further validated.

\section{Methods \\ Hypoxia mediated PH rat model and measurement of RVSP and RVH}

Sprague-Dawley rats (SPF, male, 180-200 g, 4 weeks) were obtained from the Animal Experimental Center of Zhejiang University, China. Rats were maintained in a normobaric normoxia $\left(\mathrm{FiO}_{2} 21 \%, n=6\right)$ or hypoxic chamber $\left(\mathrm{FiO}_{2} 10 \%\right.$, $n=6)$ for 3 weeks $[3,49]$. Rats were then anesthetized by intraperitoneal injection of $1 \%$ sodium pentobarbital $(130 \mathrm{mg} /$ $\mathrm{kg}$ [ [50]. Then, rats were fixed in supine position on the board. All of the operations were performed after rats were 


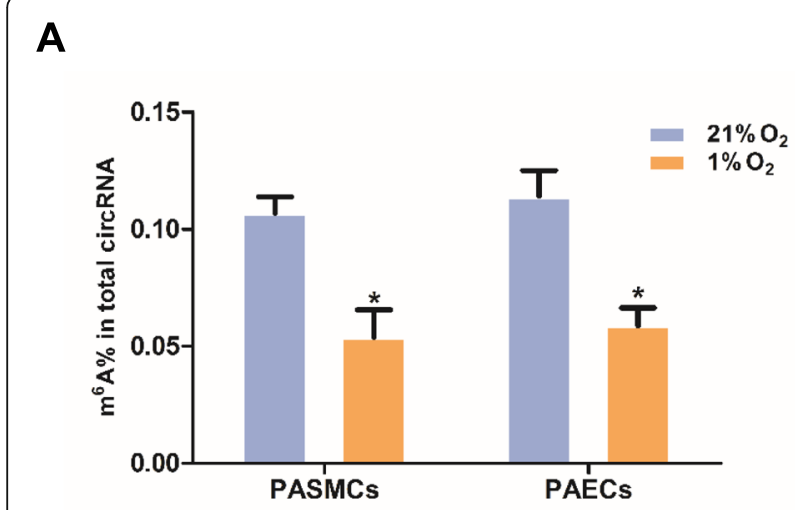

B
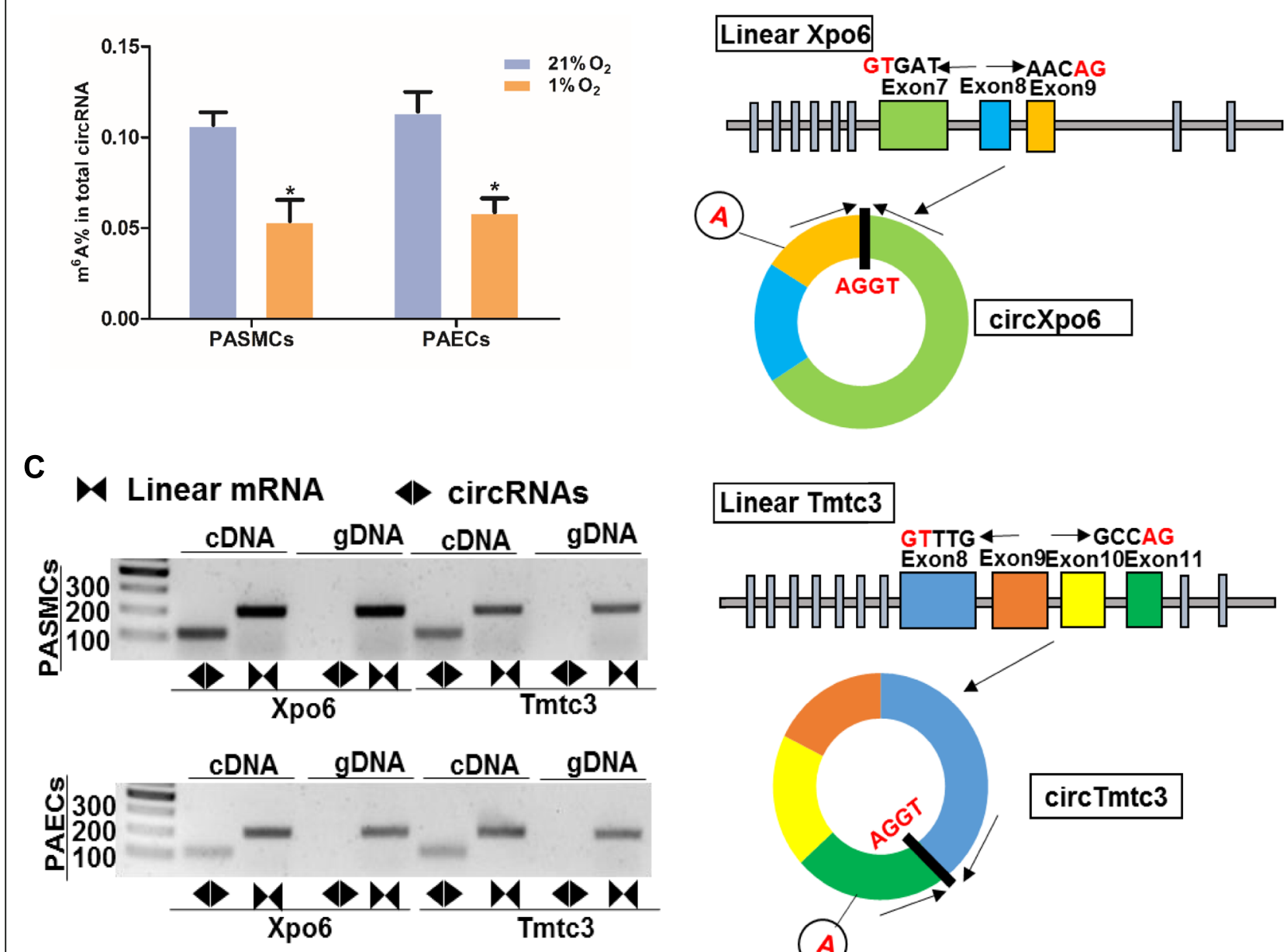

C

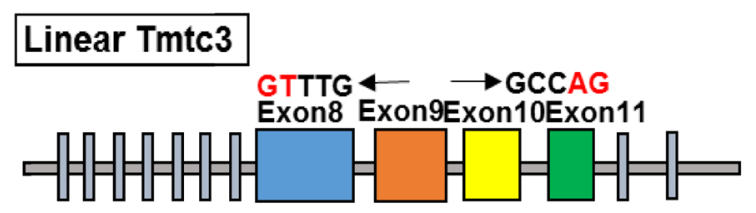

D

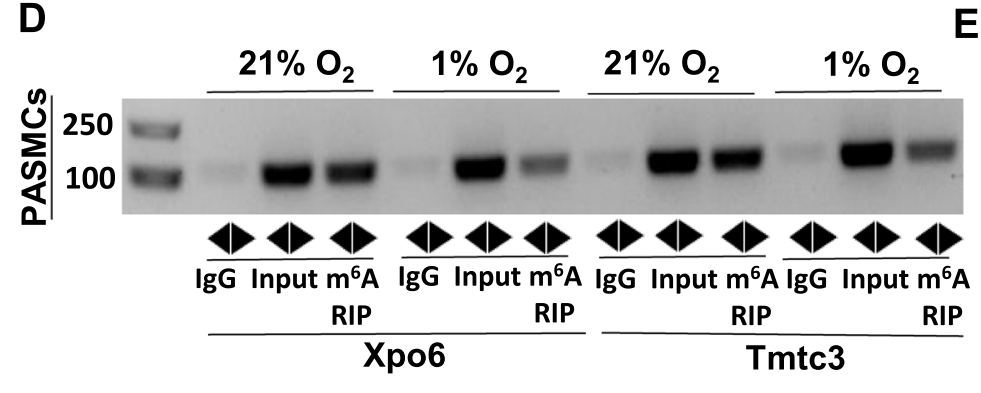

E
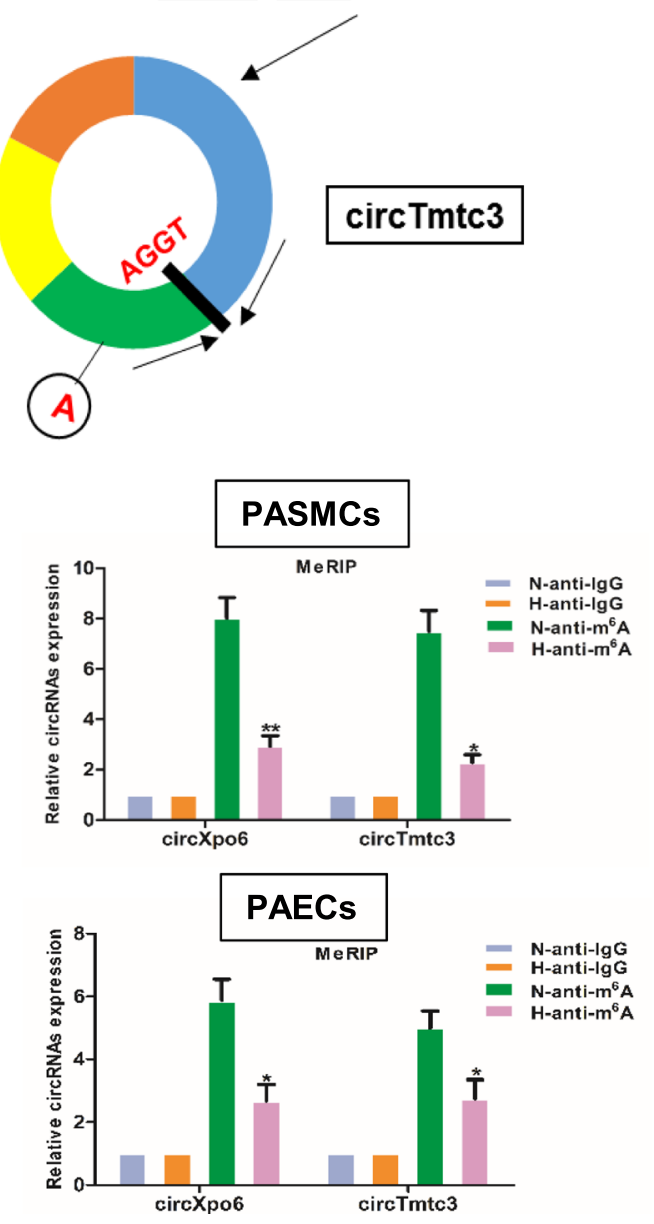

Fig. 6 (See legend on next page.) 
(See figure on previous page.)

Fig. 6 The expression profiling of $\mathrm{m}^{6} \mathrm{~A}$ circXpo6 and $\mathrm{m}^{6} \mathrm{~A}$ circTmtc3 in pulmonary arterial smooth muscle cells (PASMCs) and pulmonary artery endothelial cells (PAECs) in hypoxia. a $\mathrm{M}^{6} \mathrm{~A}$ levels of total circRNAs were determined based on colorimetric method in vitro. PASMCs and PAECS were exposed to $21 \% \mathrm{O}_{2}$ and $1 \% \mathrm{O}_{2}$ for $48 \mathrm{~h}$, respectively. Total RNA was extracted and treated by RNase R. M ${ }^{6} \mathrm{~A}$ levels were determined as a percentage of total circRNAs. $\mathbf{b}$ Schematic representation of exons of the Xpo6 and Tmtc3 circularization forming circXpo6 and circTmtc3 (black arrow). c RT-PCR validation of circXpo6 and circTmtc3 in PASMCs and PAECs exposed to $21 \% \mathrm{O}_{2}$. Divergent primers amplified circRNAs in cDNA, but not in genomic DNA (gDNA). The size of the DNA marker is indicated on the left of the gel. $\mathbf{d}$ and $\mathbf{e}$ RT-PCR and qRT-PCR was performed after $m^{6} A$ RIP in PASMCs and PAECs exposed to $21 \%(\mathrm{~N})$ and $1 \% \mathrm{O}_{2}(\mathrm{H})$ for $48 \mathrm{~h}$, respectively. Input was used as a control (d). IgG was used as a negative control (d and $\mathbf{e}$ ). Values are presented as means \pm SD. ${ }^{*} P \leq 0.05$ (different from $21 \% \mathrm{O}_{2}$ or the $\mathrm{N}$-anti-m ${ }^{6} \mathrm{~A}$ ); ${ }^{* *} 0.001 \leq P \leq 0.009$ (different from the $N$-anti- $\left.\mathrm{m}^{6} \mathrm{~A}\right),(n=3$ each)

anesthetized and became unconscious. RVSP was measured as below. Right ventricle catheterization was performed through the right jugular using a pressure-volume loop catheter (Millar) as the previous reports $[49,51]$. After measurement of RVSP, all rats were put into a confined and transparent euthanasia device (to observe whether the rats were sacrificed), then $100 \% \mathrm{CO}_{2}$ was released into the device continuously until all the rats sacrificed. The criteria for sacrifice were that rats did not have spontaneous breath for 2$3 \mathrm{~min}$ and blink reflex. Then, heart tissues were removed and segregated. The ratio of $[\mathrm{RV} /(\mathrm{LV}+\mathrm{S})]$ was used as an index of RVH. Lung were removed and immediately frozen at liquid nitrogen or fixed in $4 \%$ buffered paraformaldehyde solution. All experimental procedures were conducted in line with the principles approved by the Institutional Animal Care and Use Committee of Zhejiang University.

\section{Histological analysis}

Lung tissues were embedded in paraffin, sectioned at $4 \mu \mathrm{m}$ and stained with hematoxylin and eosin (H\&E) and $\alpha$-smooth muscle actin ( $\alpha$-SMA, 1:100, ab124964, Abcam, USA). The ratio of pulmonary small artery wall thickness and muscularization were calculated [3].

\section{Isolation and hypoxia-treatment of PASMCs and PAECs} PASMCs and PAECs were isolated using the methods according to previous reports [32, 50, 52]. PASMCs and PAECs were cultured in Dulbecco's modified Eagle's medium supplemented with $10 \%$ fetal bovine serum (FBS) and 20\% FBS for $48 \mathrm{~h}$, respectively $[32,53]$. The cells were incubated in a $37^{\circ} \mathrm{C}, \quad 21 \% \quad \mathrm{O}_{2}$ or $1 \% \mathrm{O}_{2}-5 \% \quad \mathrm{CO}_{2}$ humidified incubator. PASMCs at $70-80 \%$ confluence in 4 to 7 passages were used in experiments. PAECs at 80 $90 \%$ confluence in 4 to 5 passages were used in experiments [54].

\section{RNA isolation and RNA-seq analysis of circRNAs}

Total RNA (10 mg) was obtained using TRIzol reagent (Invitrogen, Carlsbad, CA, USA) from lungs (1 g) of control and $\mathrm{HPH}$ rats. The extracted RNAs were purified with Rnase R (RNR07250, Epicentre) digestion to remove linear transcripts. Paired-end reads were harvested from Illumina Hiseq Sequence after quality filtering. The reads were aligned to the reference genome (UCSC RN5) with STAR software. CircRNAs were detected and annotated with CIRI software [55]. Raw junction reads were normalized to per million number of reads mapped to the genome with $\log 2$ scaled.

\section{MeRIP and library preparation}

Total RNA was extracted as the methods described above. Then, rRNA was depleted following DNase I treatment. RNase R treatment (5 units/mg) was performed in duplicate with $5 \mathrm{mg}$ of rRNA-depleted RNA input. High-throughput $\mathrm{m}^{6} \mathrm{~A}$ and circRNAs sequencing were performed by Cloudseq Biotech Inc. (Shanghai, China). Fragmented RNA was incubated with anti- $\mathrm{m}^{6} \mathrm{~A}$ polyclonal antibody (Synaptic Systems, 202,003) in IPP buffer for $2 \mathrm{~h}$ at $4{ }^{\circ} \mathrm{C}$. The mixture was then incubated with protein $\mathrm{A} / \mathrm{G}$ magnetic beads $(88,802$, Thermo Fisher) at $4{ }^{\circ} \mathrm{C}$ for an additional $2 \mathrm{~h}$. Then, bound RNA was eluted from the beads with $\mathrm{N}^{6}$-methyladenosine (PR3732, BERRY \& ASSOCIATES) in IPP buffer and

Table 1 Primers for RT-PCR or qRT-PCR

\begin{tabular}{lll}
\hline Name & Sequence & Product size(bp) \\
\hline linear Xpo6 & Sense: 5'CTGTGTTTGGGTCAGGAGC3' & 199 \\
linear Tmtc3 & Antisense: 5'ATCGAGTCCTCTAGCCTGC3' & 203 \\
& Sense: 5'ACTCTGCTGTGATTGGACCA3' & 101 \\
circXpo6 & Antisense:5'AGAAGAGGTTGATGCGGGA3' & 100 \\
& Sense: 5'TCTGGGAGACAAGGAAGCAG3' & 100 \\
\hline
\end{tabular}


extracted with Trizol reagent (15,596,026, Thermo Fisher). NEBNext $^{\circ}$ Ultra $^{\text {Tu }}$ RNA Library Prep Kit (E7530L, NEB) was used to construct RNA-seq library from immunoprecipitated RNA and input RNA. The $\mathrm{m}^{6} \mathrm{~A}-\mathrm{IP}$ and input samples were subjected to $150 \mathrm{bp}$ paired-end sequencing on Illumina HiSeq sequencer. Methylated sites on circRNAs were identified by MetPeak software.

\section{Construction of circRNA-miRNA-mRNA co-expression network}

The circRNA-miRNA-mRNA co-expression network was based on the ceRNA theory that circRNA and mRNA shared the same MREs [45, 46]. Cytoscape was used to visualize the circRNA-miRNA-mRNA interactions based on the RNA-seq data. The circRNA-miRNA interaction and miRNA-mRNA interaction of interest were predicted by TargetScan and miRanda.

\section{Measurement of Total $m^{6} A$, MeRIP-RT-PCR and MeRIP- qRT-PCR}

Total $\mathrm{m}^{6} \mathrm{~A}$ content was measured in $200 \mathrm{ng}$ aliquots of total RNA extracted from PASMCs and PAECs exposed to $21 \% \mathrm{O}_{2}$ and $1 \% \mathrm{O}_{2}$ for $48 \mathrm{~h}$ using an $\mathrm{m}^{6} \mathrm{~A}$ RNA methylation quantification kit (P-9005, Epigentek). MeRIP (17701 , Millipore) was performed according to the manufacturer's instruction. A $1.5 \mathrm{~g}$ aliquot of anti- ${ }^{6} \mathrm{~A}$ antibody (ABE572, Millipore) or anti-IgG (PP64B, Millipore) was conjugated to protein $\mathrm{A} / \mathrm{G}$ magnetic beads overnight at $4{ }^{\circ} \mathrm{C}$. A $100 \mathrm{ng}$ aliquot of total RNA was then incubated with the antibody in IP buffer supplemented with RNase inhibitor and protease inhibitor. The RNA complexes were isolated through phenol-chloroform extraction (P1025, Solarbio) and analyzed via RT-PCR or qRT-PCR assays. Primers sequences are listed in Table 1.

\section{Data analysis}

3' adaptor-trimming and low quality reads were removed by cutadapt software (v1.9.3). Differentially methylated sites were identified by the $\mathrm{R}$ MeTDiff package. The read alignments on genome could be visualized using the tool IGV. Differentially expressed circRNAs were identified by Student's $t$-test. GO and KEGG pathway enrichment analysis were performed for the corresponding parental mRNAs of the DE circRNAs. GO enrichment analysis was performed using the $\mathrm{R}$ topGO package. KEGG pathway enrichment analysis was performed according to a previous report [56]. GO analysis included BP analysis, CC analysis, and MF analysis. MicroRNAs sponged by the target genes were predicted by TargetScan and microRNA websites. $P$ values are calculated by DAVID tool for GO and KEGG pathway analysis. The rest statistical analyses were performed with SPSS 19.0 (Chicago, IL, USA) and GraphPad Prism 5 software (La Jolla, CA). $\mathrm{N}$ refers to number of samples in figure legends. The statistical significance was determined by Student's $t$-test (two-tailed) or two-sided Wilcoxon-Mann-Whiteney test. $P<0.05$ was considered statistically significant. All experiments were independently repeated at least three times.

\section{Supplementary information}

Supplementary information accompanies this paper at https://doi.org/10. 1186/s12864-020-6462-y.

Additional file 1: Data S1. Differentially expressed $m^{6} \mathrm{~A}$ abundance in circRNAs.

Additional file 2: Data S2. Differentially expressed $\mathrm{m}^{6} \mathrm{~A}$ abundance linked with differentially expressed circRNAs abundance.

Additional file 3. Differentially expressed $\mathrm{m}^{6} \mathrm{~A}$ circRNAs in the lungs of $\mathrm{HPH}$ rat model.

Additional file 4. Differentially expressed circRNAs in the lungs of HPH rat model.

\section{Abbreviations}

ALKBH5: Alkylation repair homolog 5; BMP2: Bone morphogenetic protein 2: BP: Biological process analysis; CC: Cellular component analysis; CeRNA: Competing endogenous RNA; circRNAs: Circular RNAs;

COPD: Chronic obstructive pulmonary disease; Dusp1: Dual Specificity Protein Phosphatase 1; FAM134B: Family with Sequence Similarity 134, Member B; FOXM1: Forkhead Box protein M1; FTO: Fat mass and obesity related protein; Glut1: Glucose Transporter 1; GO: Gene ontology analysis; Hes1: Hairy and Enhancer of Split 1; HIF-1a, HIF-2a: Hypoxia-inducible factor1a,-2a; HPH: Hypoxia mediated pulmonary hypertension; Jun: Jun ProtoOncogene AP-1 Transcription Factor Subunit; KEGG: Kyoto Encyclopedia of Genes and Genomes; KIAA1429: Vir like m6A methyltransferase associated; LncRNA: Long non-coding RNA; ${ }^{6}$ A: N6-methyladenosine; MeRIP: M ${ }^{6}$ A RNA Immunoprecipitation; MeRIP-qRT-PCR: MeRIP-quantitative RT-PCR; METTL3, METTL14, METTL16: Methyltransferase-like-3, - 14 and - 16; MF: Molecular functions analysis; MREs: MiRNA response elements; Myc: Myc protooncogene bHLH transcription factor; ncRNAs: Noncoding RNAs; NMDAR1: Nmethyl-D-aspartate receptor 1; PAECs: Pulmonary artery endothelial cells; PASMCs: Pulmonary artery smooth muscle cells; PDGF-BB: Platelet derived growth factor beta polypeptide b; PH: Pulmonary hypertension;

PPaR: Peroxisome proliferator-activator; RBM15: RNA binding motif protein 15; RP11: RP11-138 J23.1; RVH: Right ventricular hypertrophy; RVSP: Right ventricular systolic pressure; WTAP: Wilms tumor 1-associated protein; YTHDF1, YTHDF2, YTHDF3, YTHDC1, YTHDC2: YT521-B homology domaincontaining proteins family; ZC3H13: Zinc finger CCCH-type containing 13

\section{Acknowledgements}

We thanked all subjects who participated in this study. We thank Cloud-Seq Biotech Ltd. Co. (Shanghai, China) for the MeRIP-Seq service and the subsequent bioinformatics analysis.

\section{Authors' contributions}

HS performed the experiments, analyzed the data, and made the figures; GWW, LFW and XQM analyzed the results; KYY and RFZ designed the study, analyzed the data, explained the findings and wrote the paper. All authors read and approved the final manuscript.

\section{Funding}

This study was supported by the National Natural Science Foundation of China (81570043), the National Natural Science Foundation of China (81270107), the Zhejiang Provincial Natural Science Foundation of China (LY19H010003). The funders had no role in study design, data collection and analysis, decision to publish, or preparation of the manuscript.

\section{Availability of data and materials}

The raw high-throughput $\mathrm{m}^{6} \mathrm{~A}$ and circRNAs sequencing generated during the current study has been uploaded into the repository named Zenodo, the persistent web links are https://doi.org/10.5281/zenodo.3596039, https://doi. org/10.5281/zenodo.3596178, https://doi.org/10.5281/zenodo.3596016, and https://doi.org/10.5281/zenodo.3596276. 


\section{Ethics approval and consent to participate}

The protocol of this research was submitted to and approved by the Institutional Animal Care and Use Committee of Zhejiang University, China (permit number: SYXK 2017-0006).

\section{Consent for publication}

Not Applicable.

\section{Competing interests}

The authors declare that they have no competing interests.

Received: 5 September 2019 Accepted: 8 January 2020

Published online: 13 January 2020

\section{References}

1. Pugliese SC, Poth JM, Fini MA, Olschewski A, El Kasmi KC, Stenmark KR. The role of inflammation in hypoxic pulmonary hypertension: from cellular mechanisms to clinical phenotypes. Am J Physiol Lung Cell Mol Physiol. 2015;308:L229-52.

2. Galiè N, Humbert M, Luc Vachiery J, Gibbs S, Lang I, Torbicki A, et al. ESC/ ERS guidelines for the diagnosis and treatment of pulmonary hypertension. Eur Respir J. 2015;2015(46):879-82.

3. Zhang RF, Shi LH, Zhou L, Zhang GS, Wu XH, Shao FC, et al. Transgelin as a therapeutic target to prevent hypoxic pulmonary hypertension. Am J Physiol Lung Cell Mol Physiol. 2014;306:L574-83.

4. Ball MK, Waypa GB, Mungai PT, Nielsen JM, Czech L, Dudley VJ, et al, Regulation of hypoxia-induced pulmonary hypertension by vascular smooth muscle hypoxia-inducible factor-1alpha. Am J Respir Crit Care Med. 2014; 189(3):314-24.

5. Meng X, Li X, Zhang P, Wang J, Zhou Y, Chen M. Circular RNA: an emerging key player in RNA world. Brief Bioinform. 2017;18(4):547-57.

6. Salzman J. Circular RNA expression: its potential regulation and function. Trends Genet. 2016;32(5):309-16.

7. Chen LL, Yang L. Regulation of circRNA biogenesis. RNA Biol. 2015;12(4):381-8.

8. Pamudurti NR, Bartok O, Jens M, Ashwal-Fluss R, Stottmeister C, Ruhe L, et al. Translation of CircRNAs. Mol Cell. 2017;66(1):1-13.

9. Yang $Y$, Fan $X$, Mao $M$, Song $X$, Wu P, Zhang $Y$, et al. Extensive translation of circular RNAs driven by N(6)-methyladenosine. Cell Res. 2017;27(5):626-41.

10. Boeckel JN, Jae N, Heumuller AW, Chen W, Boon RA, Stellos K, et al. Identification and characterization of hypoxia-regulated endothelial circular RNA. Circ Res. 2015;117(10):884-90.

11. Dang RY, Liu FL, Li Y. Circular RNA hsa_circ_0010729 regulates vascular endothelial cell proliferation and apoptosis by targeting the miR-186/HIF1alpha axis. Biochem Biophys Res Commun. 2017;490(2):104-10.

12. Wang J, Zhu MC, Kalionis B, Wu JZ, Wang LL, Ge HY, et al. Characteristics of circular RNA expression in lung tissues from mice with hypoxiainduced pulmonary hypertension. Int J Mol Med. 2018;42(3):1353-66.

13. Chen K, Lu Z, Wang X, Fu Y, Luo GZ, Liu N, et al. High-resolution N(6) -methyladenosine $(\mathrm{m}(6)$ a) map using photo-crosslinking-assisted $\mathrm{m}(6)$ a sequencing. Angew Chem. 2015;54(5):1587-90.

14. Zhou C, Molinie B, Daneshvar K, Pondick JV, Wang J, Van Wittenberghe N, et al. Genome-wide maps of m6A circRNAs identify widespread and celltype-specific methylation patterns that are distinct from mRNAs. Cell Rep. 2017;20(9):2262-76.

15. Zheng $Y$, Nie $P$, Peng $D$, He $Z$, Liu $M$, Xie $Y$, et al. m6AVar: a database of functional variants involved in m6A modification. Nucleic Acids Res. 2018; 46(D1):D139-45.

16. Xuan JJ, Sun WJ, Lin PH, Zhou KR, Liu S, Zheng LL, et al. RMBase v2.0: deciphering the map of RNA modifications from epitranscriptome sequencing data. Nucleic Acids Res. 2018;46(D1):D327-34.

17. Wang $S$, Chai $P$, Jia R, Jia R. Novel insights on m(6)a RNA methylation in tumorigenesis: a double-edged sword. Mol Cancer. 2018;17(1):101.

18. Dai $D$, Wang H, Zhu L, Jin H, Wang X. N6-methyladenosine links RNA metabolism to cancer progression. Cell Death Dis. 2018;9(2):124.

19. Meyer KD, Saletore Y, Zumbo P, Elemento O, Mason CE, Jaffrey SR. Comprehensive analysis of mRNA methylation reveals enrichment in $3^{\prime}$ UTRs and near stop codons. Cell. 2012;149(7):1635-46.

20. Wang X, Huang J, Zou T, Yin P. Human m(6)a writers: two subunits, 2 roles. RNA Biol. 2017;14(3):300-4.

21. Deng X, Su R, Weng H, Huang H, Li Z, Chen J. RNA N(6)-methyladenosine modification in cancers: current status and perspectives. Cell Res. 2018;28(5):507-17.
22. Wu B, Li L, Huang Y, Ma J, Min J. Readers, writers and erasers of N(6)methylated adenosine modification. Curr Opin Struct Biol. 2017:47:67-76.

23. Liao S, Sun H, Xu C. YTH domain: a family of N(6)-methyladenosine (m(6)a) readers. Genomics Proteomics Bioinformatics. 2018;16(2):99-107.

24. Patil DP, Pickering BF, Jaffrey SR. Reading $m(6) a$ in the Transcriptome: m(6)A-binding proteins. Trends Cell Biol. 2018;28(2):113-27.

25. Panneerdoss S, Eedunuri VK, Yadav P, Timilsina S, Rajamanickam S, Viswanadhapalli $S$, et al. Cross-talk among writers, readers, and erasers of m6A regulates cancer growth and progression. Sci Adv. 2018;4:eaar8263.

26. Zhang C, Samanta D, Lu H, Bullen JW, Zhang H, Chen I, et al. Hypoxia induces the breast cancer stem cell phenotype by HIF-dependent and ALKBH5-mediated m(6)A-demethylation of NANOG mRNA. Proc Natl Acad Sci. 2016;113(14):E2047-56.

27. Rowan SC, Keane MP, Gaine S, McLoughlin P. Hypoxic pulmonary hypertension in chronic lung diseases: novel vasoconstrictor pathways. Lancet Respir Med. 2016;4(3):225-36.

28. Chan JJ, Tay Y. Noncoding RNA:RNA regulatory networks in Cancer. Int J Mol Sci. 2018;19(5):1310.

29. Baarsma HA, Konigshoff M. 'WNT-er is coming': WNT signalling in chronic lung diseases. Thorax. 2017;72(8):746-59.

30. de Jesus PV, Yuan K, Alastalo TP, Spiekerkoetter E, Rabinovitch M. Targeting the Wnt signaling pathways in pulmonary arterial hypertension. Drug Discov Today. 2014;19(8):1270-6.

31. Savai R, Al-Tamari HM, Sedding D, Kojonazarov B, Muecke C, Teske R, et al. Proproliferative and inflammatory signaling converge on FoxO1 transcription factor in pulmonary hypertension. Nat Med. 2014;20(11):1289-300.

32. Su H, Xu X, Yan C, Shi Y, Hu Y, Dong L, et al. LncRNA H19 promotes the proliferation of pulmonary artery smooth muscle cells through AT1R via sponging let-7b in monocrotaline-induced pulmonary arterial hypertension. Respir Res. 2018;19(1):254.

33. Caruso P, MacLean MR, Khanin R, McClure J, Soon E, Southgate M, et al. Dynamic changes in lung microRNA profiles during the development of pulmonary hypertension due to chronic hypoxia and monocrotaline. Arterioscler Thromb Vasc Biol. 2010;30(4):716-23.

34. Zhong X, Yu J, Frazier K, Weng X, Li Y, Cham CM, et al. Circadian clock regulation of hepatic lipid metabolism by modulation of m(6)a mRNA methylation. Cell Rep. 2018;25(7):1816-28.

35. Dorn $L E$, Lasman $L$, Chen J, Xu X, Hund TJ, Medvedovic M, et al. The N(6)Methyladenosine mRNA Methylase METTL3 controls cardiac homeostasis and hypertrophy. Circulation. 2019;139(4):533-45.

36. Yang DD, Qiao J, Wang GY, Lan YY, Li GP, Guo XD, et al. N ${ }^{6}$ Methyladenosine modification of lincRNA 1281 is critically required for mESC differentiation potential, vol. 46; 2018.

37. Nate J. Fry BAL, Olga R. Ilkayeva, Christopher L. Holley, and Kyle D. Mansfield: N6-methyladenosine is required for the hypoxic stabilization of specific mRNAs. Rna 2017, 23(9):1444-1455.

38. Song $H$, Feng $X$, Zhang H, Luo Y, Huang J, Lin M, et al. METTL3 and ALKBH5 oppositely regulate $m(6)$ a modification of TFEB mRNA, which dictates the fate of hypoxia/reoxygenation-treated cardiomyocytes. Autophagy. 2019:1-19.

39. Luo GZ, MacQueen A, Zheng G, Duan H, Dore LC, Lu Z, et al. Unique features of the m6A methylome in Arabidopsis thaliana. Nat Commun. 2014:5:5630.

40. Wu Y, Yang $X$, Chen Z, Tian L, Jiang G, Chen F, et al. m(6)A-induced IncRNA RP11 triggers the dissemination of colorectal cancer cells via upregulation of Zeb1. Mol Cancer. 2019;18(1):87.

41. Yao Y, Bi Z, Wu R, Zhao Y, Liu Y, Liu Q, et al. METTL3 inhibits BMSC adipogenic differentiation by targeting the JAK1/STAT5/C/EBPbeta pathway via an m(6)A-YTHDF2-dependent manner. FASEB J. 2019; fj201802644R.

42. Cai $M$, Liu $Q$, Jiang $Q$, Wu $R$, Wang $X$, Wang $Y$. Loss of $m(6)$ a on FAM134B promotes adipogenesis in porcine adipocytes through $m(6)$ A-YTHDF2dependent way. IUBMB Life. 2019;71(5):580-6.

43. Chen $X$, Yu C, Guo M, Zheng X, Ali S, Huang H, et al. Down-regulation of m6A mRNA methylation is involved in dopaminergic neuronal death. ACS Chem Neurosci. 2019.

44. Fitzsimmons CM, Batista PJ. It's complicated... m(6)A-dependent regulation of gene expression in cancer. Biochim Biophys Acta Gene Regul Mech. 2019;1862(3):382-93.

45. Chen L, Zhang S, Wu J, Cui J, Zhong L, Zeng L, Ge S. circRNA_100290 plays a role in oral cancer by functioning as a sponge of the miR-29 family. Oncogene. 2017;36(32):4551-61.

46. Salmena L, Poliseno L, Tay Y, Kats L, Pandolfi PP. A ceRNA hypothesis: the Rosetta stone of a hidden RNA language? Cell. 2011;146(3):353-8. 
47. JD JW, Austin ED, Gaskill C, Baskir R, Bilousova G, Jean JC, et al. Identification of a common Wnt-associated genetic signature across multiple cell types in pulmonary arterial hypertension. Am J Physiol Cell Physiol. 2014;307:C415-30.

48. Awad H, Nolette N, Hinton M, Dakshinamurti S. AMPK and FoxO1 regulate catalase expression in hypoxic pulmonary arterial smooth muscle. Pediatr Pulmonol. 2014;49(9):885-97.

49. Cowburn AS, Crosby A, Macias D, Branco C, Colaco RD, Southwood M, et al. HIF2alpha-arginase axis is essential for the development of pulmonary hypertension. Proc Natl Acad Sci U S A. 2016;113(31):8801-6.

50. Yun X, Jiang HY, Lai N, Wang J, Shimoda LA. Aquaporin 1-mediated changes in pulmonary arterial smooth muscle cell migration and proliferation involve $\beta$ catenin. Am J Physiol Lung Cell Mol Physiol. 2017;313:L889-98.

51. Yamazato Y, Ferreira AJ, Hong KH, Sriramula S, Francis J, Yamazato M, et al. Prevention of pulmonary hypertension by angiotensin-converting enzyme 2 gene transfer. Hypertension. 2009;54(2):365-71.

52. Xiao R, Su Y, Feng T, Sun M, Liu B, Zhang J, et al. Monocrotaline induces endothelial injury and pulmonary hypertension by targeting the extracellular calcium-sensing receptor. J Am Heart Assoc. 2017;6(4):e004865.

53. Zhang HY, Liu Y, Yan LX, Du W, Zhang XD, Zhang M, et al. Bone morphogenetic protein-7 inhibits endothelial-mesenchymal transition in pulmonary artery endothelial cell under hypoxia. J Cell Physiol. 2018;233(5):4077-90.

54. Omura J, Satoh K, Kikuchi N, Satoh T, Kurosawa R, Nogi M, et al. Protective roles of endothelial AMP-activated protein kinase against hypoxia-induced pulmonary hypertension in mice. Circ Res. 2016;119(2):197-209.

55. Thomas B, Hansen MTV, Christian K. Damgaard and Jørgen Kjems: comparison of circular RNA prediction tools. Nucleic Acids Res. 2015;44(6):e58.

56. Tian L, Greenberg SA, Kong SW, Altschuler J, Kohane IS, Park PJ. Discovering statistically significant pathways in expression profiling studies. Proc Natl Acad Sci U S A. 2005;102(38):13544-9.

\section{Publisher's Note}

Springer Nature remains neutral with regard to jurisdictional claims in published maps and institutional affiliations.

Ready to submit your research? Choose BMC and benefit from:

- fast, convenient online submission

- thorough peer review by experienced researchers in your field

- rapid publication on acceptance

- support for research data, including large and complex data types

- gold Open Access which fosters wider collaboration and increased citations

- maximum visibility for your research: over $100 \mathrm{M}$ website views per year

At $\mathrm{BMC}$, research is always in progress.

Learn more biomedcentral.com/submissions 